\title{
Discussion on Improvement of Postgraduate Research Funding System in Universities
}

\author{
Guilin Gao \\ Capital University of Economics and Business \\ Beijing, China \\ Email: Gaoguilinrenda@163.com
}

\begin{abstract}
The academic research ability of postgraduates is an important link for postgraduate education, so each university has its own postgraduate research funding program, to cultivate the capacity for scientific research of postgraduates. However, there exist certain differences on comprehension and management implementation of postgraduate research funding program in university due to lacking of uniform rules and regulations of current top-level design on postgraduate research funding program. Meanwhile, some problems are exposed in practice. Therefore, a set of implementation rules should be standardized from the aspect of top-level design, so that postgraduate research funding system makes a real difference. Furthermore, the operation specification of postgraduate research funding program and academic research ability of postgraduates can be improved really.
\end{abstract}

\section{Keywords: Postgraduate; Scientific Research; Funding}

\section{OVERVIEW OF POSTGRADUATE RESEARCH FUNDING IN UNIVERSITIES}

\section{A. Concept of Postgraduate Research Funding in Universities}

Postgraduate research funding in universities means that the institutions of higher learning provide financial support for their postgraduates who are engaged in research work and help them to accomplish scientific research projects, to encourage postgraduates to work on scientific research activities, improve the research capacity of postgraduates, and promote the overall scientific research atmosphere of universities. Postgraduate research funding provided by institutions of higher learning is a special measure for postgraduates, which is common in universities that attach importance to scientific research. The supporting for poor students in colleges and universities, similar to postgraduate research funding in universities, refers to a system that makes impoverished students enter schools and graduate successfully. The similarity between these two systems is to provide funding for students, but the differences have two points as follows: Firstly, their purposes are different, the purpose of postgraduate research funding is to accomplish research projects for postgraduates and improve their research capacities. [1] However, the purpose of the latter is to ensure the poor students finishing their studies. Secondly, their objects are different, the objects of the former refer to postgraduates engaged in scientific research, particularly the excellent student groups with strong research ability. However, the objects of the latter are poor students who meet the required standards.

\section{B. Characteristics of Postgraduate Research Funding in Universities}

From the essential feature, the characteristics of postgraduate research funding in universities can be embodied as "five characteristics": Firstly, the specificity of the object, the subject of postgraduate research funding must be postgraduates in the university who own research ability and are outstanding graduate students passing the examination of postgraduate research funding project. Secondly, the specificity of the content, the content of postgraduate research funding is mainly scientific research innovation project, which helps postgraduates to achieve scientific research achievements. Thirdly, the specificity of purpose, the purpose of postgraduate research funding is to improve the research ability of postgraduates and enhance the overall level of scientific research. Fourthly, the specificity of the method, it mainly provide financial support for scientific research projects, so that scientific research projects can be carried out smoothly. Fifthly, the specificity of the program, postgraduate research funding has strict program restrictions. Its final approval can be obtained only passing multiple programs, including material declaration, expert review, academic committee approval, publication procedure, approval of research grant and others.[2]

\section{Implementation Status of Postgraduate Research Funding Project in University}

From the perspective of current situation, the implementation status of postgraduate research funding project in university can be summarized as "three smalls and one big".

Firstly, low funding proportion; from the perspective of practice, the postgraduate research funding project in university has total plan, the research department in university decides certain funding proportion and plan total funding of postgraduate research funding project based on the total enrollment of postgraduates per year. However, on account of slight variation of postgraduates' enrollment per year, accordingly the total funding for postgraduate research funding project changes slightly. Under normal circumstances, narrower funded aspects, less funding proportion. In other words, only a small amount of postgraduates can be subsidized for postgraduate research funding project.

Secondly, small amount of funding; In terms of the 
funding for postgraduate research funding project, it will be different in different schools under normal conditions, which is RMB3000Yuan-5000Yuan at least and about ten thousand Yuan at most. According to practice, it often require more funding for scientific research of postgraduates, especially doctoral candidates; of which only cost of publication can exceed the total amount of expenditure. In other words, the postgraduates, under most circumstances, may provide expenditure by themselves for postgraduate research funding project.

Thirdly, great declaration difficulty; from the point of practice, not everyone can apply postgraduate research funding project. Due to program mechanism design, many projects with certain scientific value are not funded, while some projects with little scientific value are funded. Hence, it is difficult for postgraduates to apply for scientific research projects under many circumstances.

Fourthly, small implement achievements; the purpose of postgraduate research funding project is to improve scientific research ability of postgraduates and enhance the whole research level. From the perspective of practice, many students, especially doctoral candidate, apply for funding support successfully but it is insufficient. Besides, since facing with greater life pressure, the enthusiasm of postgraduates in scientific research is decreased greatly. A great number of postgraduates who are unwilling to engage in scientific research, so the postgraduate research funding project had poor implementation effect on the whole.[3]

\section{II.PRACTICAL DIFFICULTIES IN THE OPERATION OF POSTGRADUATE RESEARCH FUNDING IN COLLEGES AND UNIERSITIES}

Currently, the practical difficulties in the operation process of postgraduate research funding project in university are mainly manifested as "three difficulties and one big".

\section{A. Different Project Approval}

The project approval of postgraduate research funding project requires stricter approval procedures, which should be determined by academic committee of school after obtaining review suggestions of experts. However, the academic committee of school is not familiar to all majors, so some cross-disciplinary, research-worthy projects are difficult to be approved.

\section{B. Difficult Supervision}

In practice, some postgraduates are short of earnest and serious attitude during scientific research process after project approval due to lacking of improved supervision approach in universities, while some postgraduates who have earnest attitude fail to obtain the due reward.

\section{Difficult Project Closure}

A great number of colleges and universities develop more stringent requirements on project closure of postgraduate research projects, even a requirement on the publication of a journal grade, to improve research ability and level, and to obtain better achievements in comprehensive ranking. Hence, it is difficult to close an project.

\section{Great Resistance}

From the implementation of postgraduate research funding projects in university, numerous postgraduates are not interested in scientific research and are unwilling to engage in scientific research. It is difficult for the scientific research department to provide comprehensive management and assistance in the process of operation; meanwhile, the project closure also exists difficulty, all these reasons add the resistance for operating postgraduate research funding projects.

\section{REASONS FOR THE PROBLEMS IN THE OPERARION OF POSTGRADUATE RESEARCH FUNDING PROJECTS}

In practice, various reasons can result in the problems occur in the operation of postgraduate research funding, in general, they can be summarized as the following three aspects:

\section{A. Cognitive Aspect}

From cognitive aspect, the principal in many universities have no profound understanding on postgraduates' academic research. They consider that it is difficult to make achievements in scientific research due to limited ability, so they are not very supportive of postgraduate research projects. Besides, the principal in some universities hold that it will waste much funding for postgraduate research project due to inadequate funding; however, some universities set up high standard on postgraduate research project, in order to seek for excellent achievements, this thinking that is anxious to achieve quick success and get instant benefits also increase the difficulty of postgraduate research projects.

\section{B. Institutional Norm}

At present, the state has insufficient stipulations on postgraduate research funding projects. Although the application platform for postgraduate education innovation program has been established by Ministry of Education, the postgraduate research funding project is basically controlled by the university. Meanwhile, the Ministry of Education has no uniform institutional norm on postgraduate research funding, each university has various approach on postgraduate research funding, and even the systematic criteria are different at different years in the same school, in consequence, the postgraduate research funding exists certain confusion phenomena.

\section{Practical Operation}

On account of different financial resources, each university has different management style and financial support. In particular, the requirements for closure of postgraduate research funding projects are also different in the absence of supervision of postgraduate research projects, especially for the universities have high requirements on projects closure, which not only constrains the enthusiasm of postgraduate in scientific research, but also result in some management chaos. 


\section{IMPROVEMENT OF POSTGRADUATE RESEARCH PROJECTS IN UNIERSITY}

\section{A. Top-level Design of Standardizing Postgraduate Research Projects in University}

So far, there is no explicit stipulation on the scope, conditions, procedures, strength of support, application requirements, conditions of project closure and others of the postgraduate research funding from the aspect of top-level design, which influence the standardized developing of postgraduate research funding system to a large extent. As a result, the item setting of each university on postgraduate research funding and practicing management are in the confusing state. From this point of view, the Ministry of Education should introduce the top-level design and standardize the research funding activities of postgraduates, which is the only way to standardize the implementation of postgraduate research funding. Certainly, the purpose of postgraduate research funding should be defined during top-level design, only the clear purpose can standardize the establishment and operation of the system. In view of the current status of postgraduate research funding in universities and colleges, it should be clear that the purpose of postgraduate research funding is to train postgraduates' scientific research ability in the top-level design process. Postgraduate research funding cannot be a tool to resolve the university ranking, or be defined as a way of relieving poor postgraduates, otherwise, postgraduate research funding will be likely abused.

\section{B. Improvement of Setting Conditions of Postgraduate Research Funding in University}

In practice, each university has different setting conditions for postgraduate research funding project, some projects are set as certain proportion based on enrollment of postgraduates, some projects are set as fixed proportion, and some other are covered comprehensively. Consequently, the setting of postgraduate research funding project changes in different universities, which is controlled by its own university usually. Hence, the setting condition of postgraduate research funding must be defined when conducting top-level design, to avoid the confusing phenomena of postgraduate research funding projects. According to practice, postgraduate research funding has certain continuity, which forms certain convention, while others are just like a flash in the pan or have no continuity. In view of this situation in practice, postgraduate student research projects can be set under the premise of the universities have continuous enrollment for a certain number of years and own sustainable financing ability, so that the stability of postgraduate student research projects can be guaranteed.

\section{Improvement of the Scope and Quantity of}

Postgraduate Research Funding in University

From the practice of previous postgraduate research funding projects, a limited number of students who receiving the funding and small amount of financial support is a prominent problem. Each university has a different level of funding and different understanding of graduate research funding, which directly affects the scope and funding of postgraduate research funding project. This uneven state of affairs is not conducive to postgraduate research. Although some universities provide funding for postgraduate student research project, it is not enough to offset the full cost of the operation of scientific research project, which will greatly reduce the enthusiasm of postgraduates to engage in academic research. Therefore, when conducting the top-level design of postgraduate research funding system, it is necessary to clarify the scope of postgraduate research funding, namely the lowest proportion and the highest proportion of coverage, which should be defined within reasonable interval. It is suggested that more than half of the coverage ratio will motivate the postgraduates to engage in academic research.[4] However, the quantity of financial support should stipulate the minimum funding support ratio, which should cover total costs before project closure. It is suggested that the dynamic application system should be carried out for postgraduate research funding projects, of which a scope should be set up, and the applicants apply the funding according to budget status within this amount range. Therefore, the unreasonable allocation of research funding resulted by "sweeping approach", for example, fixed issue of subvention can be avoided.

\section{Improvement of Application Requirement of} Postgraduate Research Funding in University

Under normal circumstances, the application requirements of postgraduate research funding are determined by research office in university according to comprehensive abilities, number of postgraduates and proportion of postgraduate research funding. Because of disordered application requirements of postgraduate research funding in practice, the conditions set by each school for postgraduate research funding are different. Therefore, it is very necessary to define the application conditions of postgraduate student research projects, to standardize postgraduate student research funding system. It is suggested that the Ministry of Education should regulate the basic conditions of postgraduate student research projects, if universities have further provisions on application conditions, the basic conditions can be increased. According to practice, the application conditions of the postgraduate research funding project should be divided into two categories, one is the application condition of the ordinary project. The novelty, specialty, feasibility and other aspects of application projects should be investigated emphatically, so it should stipulate that the applicant should make a rational explanation for the novelty, specialty and feasibility, which have the basic conditions of the application only if meeting this condition. The second category is the application conditions of major projects. For major projects, the novelty, specialty and feasibility of application project should be inspected emphatically, in addition, the previous research results of applicants will be also investigated. If the above two parts are not complete, it will illustrate that the applicants have no adequate preparation or basic condition for applying major projects. 
Only stipulating the applicant conditions, the arbitrariness of practical operation can be avoided. [5]

\section{E. Improvement of Process Supervision of Postgraduate Research Funding in University}

An outstanding issue of postgraduate research funding in university in implementation process is lacking authority when subsidizing project implementation. Under many circumstances, the postgraduate research funding projects are not implemented by the principal as expected after project approval, on the contrary, the report of project closure is prepared hurriedly before the deadline, which cannot have real effect of academic research. Meanwhile, it brings certain negative effect on the management of postgraduate research funding projects, so the postgraduate research funding projects will be formalized. The reason of this phenomenon is that the implementation of postgraduate research funding projects in university is short of process supervision. Based on this situation, the Ministry of Education should increase the process management during the top-level design on system of postgraduate research funding projects; besides, the mid-term examination should be regarded as a necessary condition, interim report and corresponding research achievements should be submitted in the process of the mid-term examination within a certain time limit. Otherwise, the project funding should be suspended, and the previous funding will be also recovered. Only by this way the effect of process supervision can be obtained.

\section{F. Improvement of Project Closure Standard of Postgraduate Research Funding in University}

Each university has different management system on project closure of postgraduate research funding projects, some universities may only submit research report, and some universities request to publish articles on open periodicals, while some universities ask postgraduates to publish articles on core periodicals to increase the achievements in scientific research. In view of the current standard confusion of project closure of postgraduate research funding projects, it is necessary for Ministry of Education to unify the standards of project closure for postgraduate research funding projects in the top-level design. At least the necessary standards should be set, to prevent postgraduate research funding projects from becoming a formal product or unrealistically raising the effect of postgraduate research funding projects. Hence, it is suggested that the interim results paper and project closure results paper should be submitted on the formal periodical at project closure of postgraduate research funding projects. This can avoid the occurrence of the "perfunctory closure" phenomenon caused by different standards. Certainly, some universities can also specify journals directory, to improve the scientific research strength of postgraduates, but the specified journals directory should not be the sole criterion of project closure, otherwise it will regard the postgraduate research funding projects as a tool for enhancing the academic rankings. Therefore, when specifying journals directory, it should also stipulate that it they cannot publish articles on the specified journals directory, they should provide a certain number of related publications published, which can be stipulated as three articles. Through this flexible system, the postgraduate research funding projects won't be regarded as a tool.

\section{G. Improvement of Assessment of Postgraduate Research Funding in University}

The implementation of postgraduate research funding projects should be a long-term continuous process, otherwise, it will have negative influence on continuously training of postgraduates' academic research abilities. Based on this circumstance, the Ministry of Education should clearly define that the postgraduate research funding system should be included in the process of assessment when preparing the top-level design. In addition, the postgraduate research funding activities should be evaluated every certain number of years, in order to further improve the management of postgraduate research funding. However, for the unqualified projects through assessment, the operation of postgraduate research funding project should be suspended and rectified within a given time, which cannot be carried out before the rectification is qualified.

\section{V.CONCLUSION}

The establishment of postgraduate research funding system in universities is a system for the implementation of research and innovation projects. Its purpose is to improve the academic research level of postgraduates, while the universities have great difference and some problems in the operation of postgraduate research funding projects in practice due to a great number of imperfect places in top-level design. Hence, it is necessary to stipulate some requirements for postgraduate research funding system from the top-level design level, to standardize the operation of this system. Specifically speaking, the setting conditions, scope of funding, application conditions, process supervision, criteria for project closure, assessment and other aspects of postgraduate research funding should be improved, so that it can be normalized gradually.

\section{REFERENCES}

[1] Ye Siqiao. Postgraduate Research Activities and Academic Norms [M]. China WaterPower Press. 2014.89.

[2] Capital Higher Education Development Research Base of Beijing University of Aeronautics and Astronautics. Compilation of Typical Cases of Postgraduate in Universities and Research Institutes (2012) [M]. Peking University Press, 2014.78

[3] Qi Weixin, Li Xiangyan, Zhou Min. Research on the Postgraduate Funding System - A Case Study of a Provincial Research University [J]. Accountant, 2017(11): 77

[4] Xia qingyu. Some Suggestions on Education and Scientific Research in China [J]. Daqing Social Science, 2018(1): 131

[5] Ji Guang, Zhao Zongjiang. Research Ideas and Methods [M]. People's Medical Publishing House, 2016. 213 